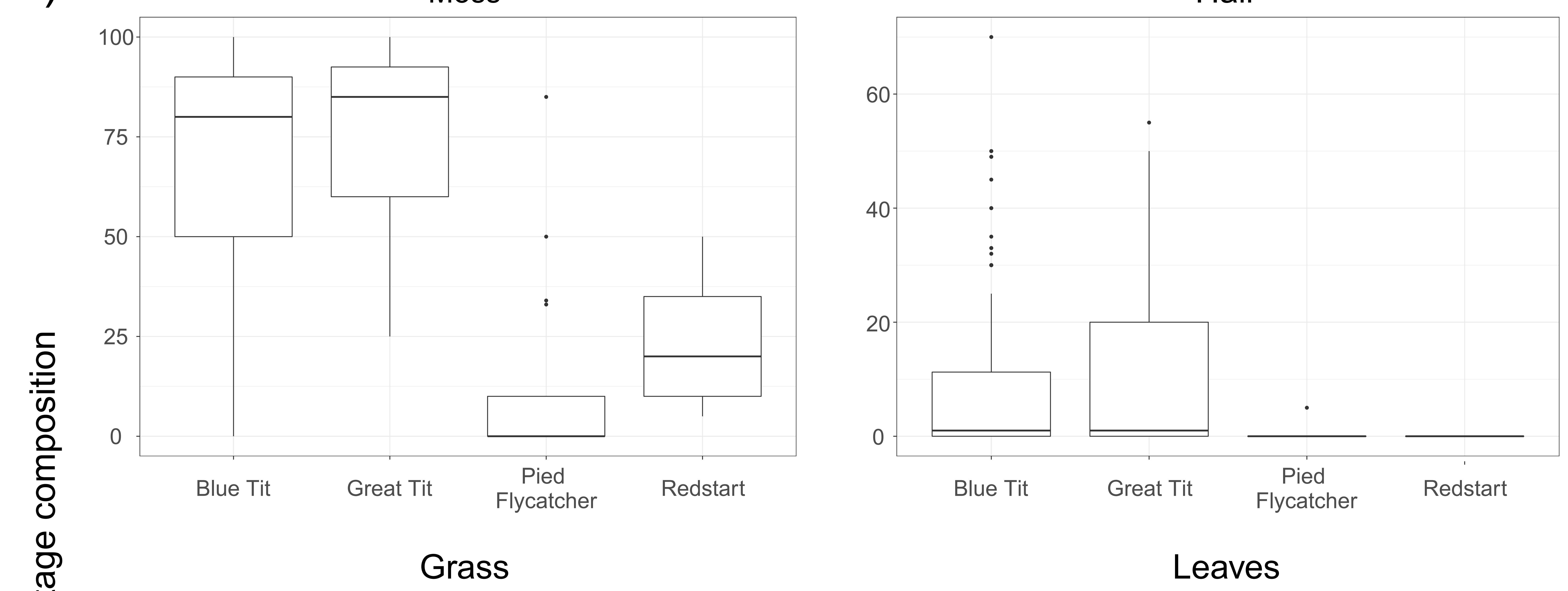

ه
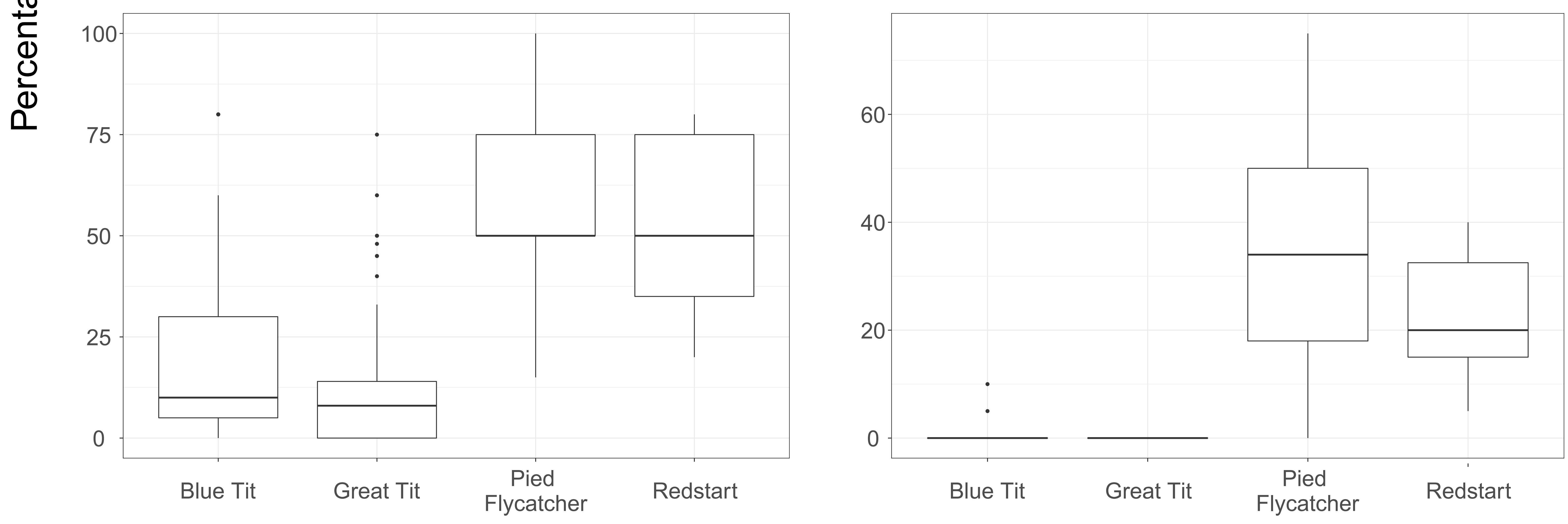

b)

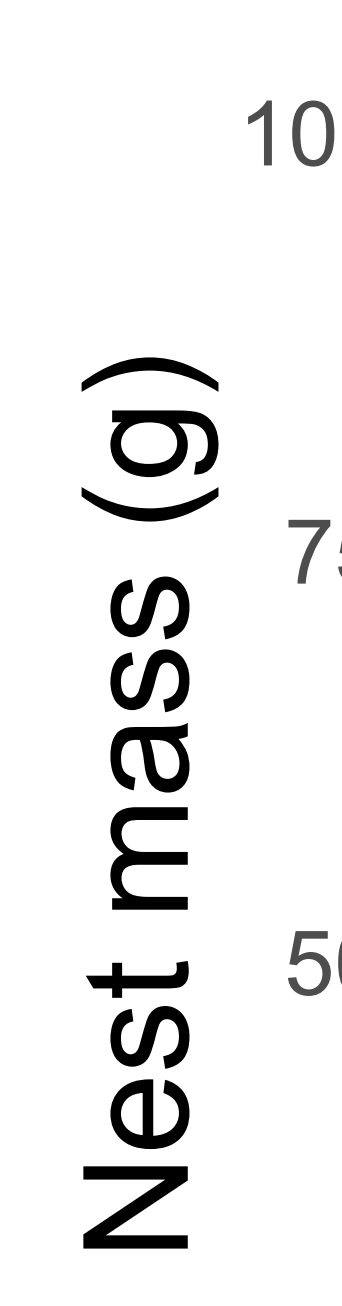

25

0

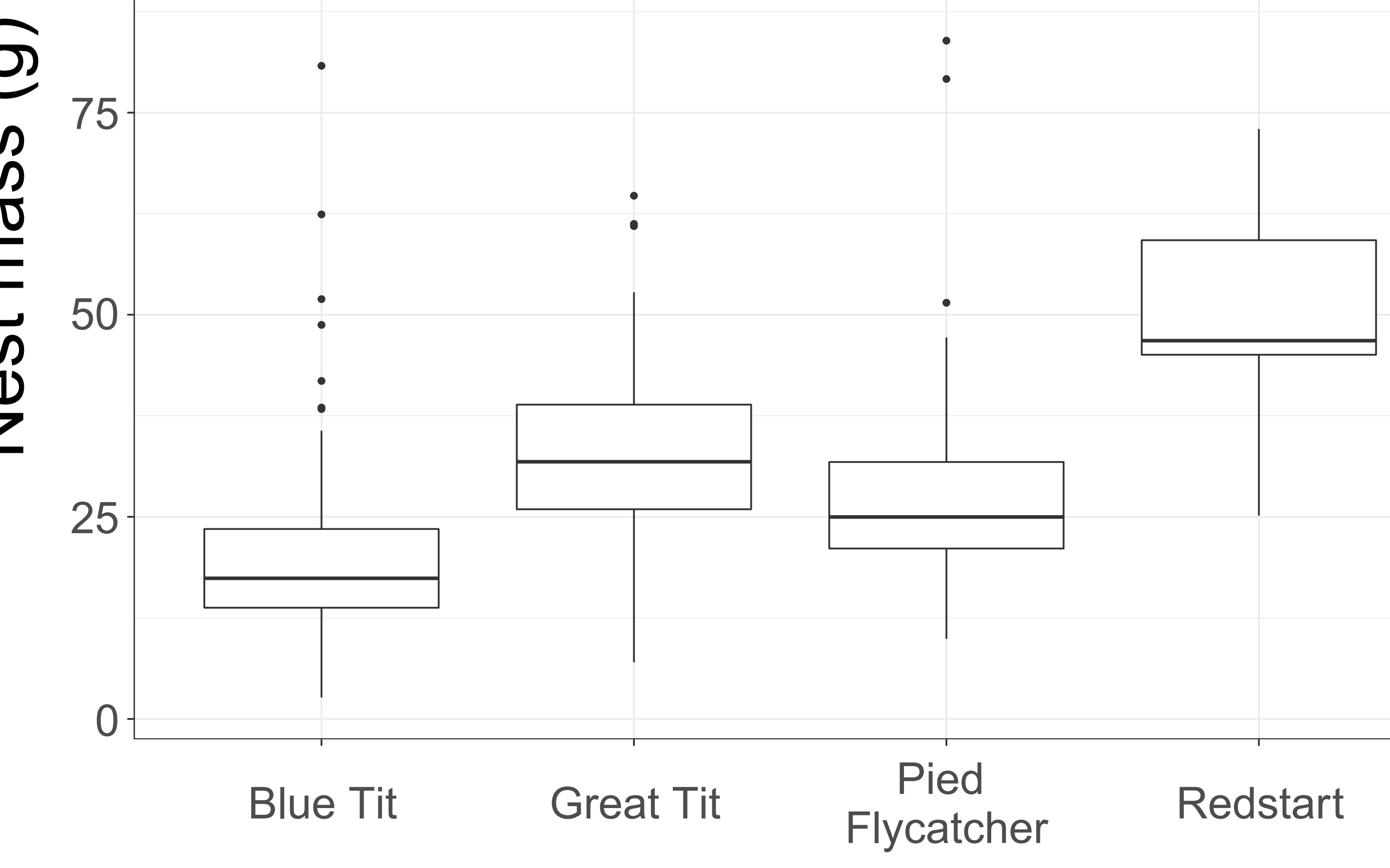

Bird species

\title{
Bird species
}




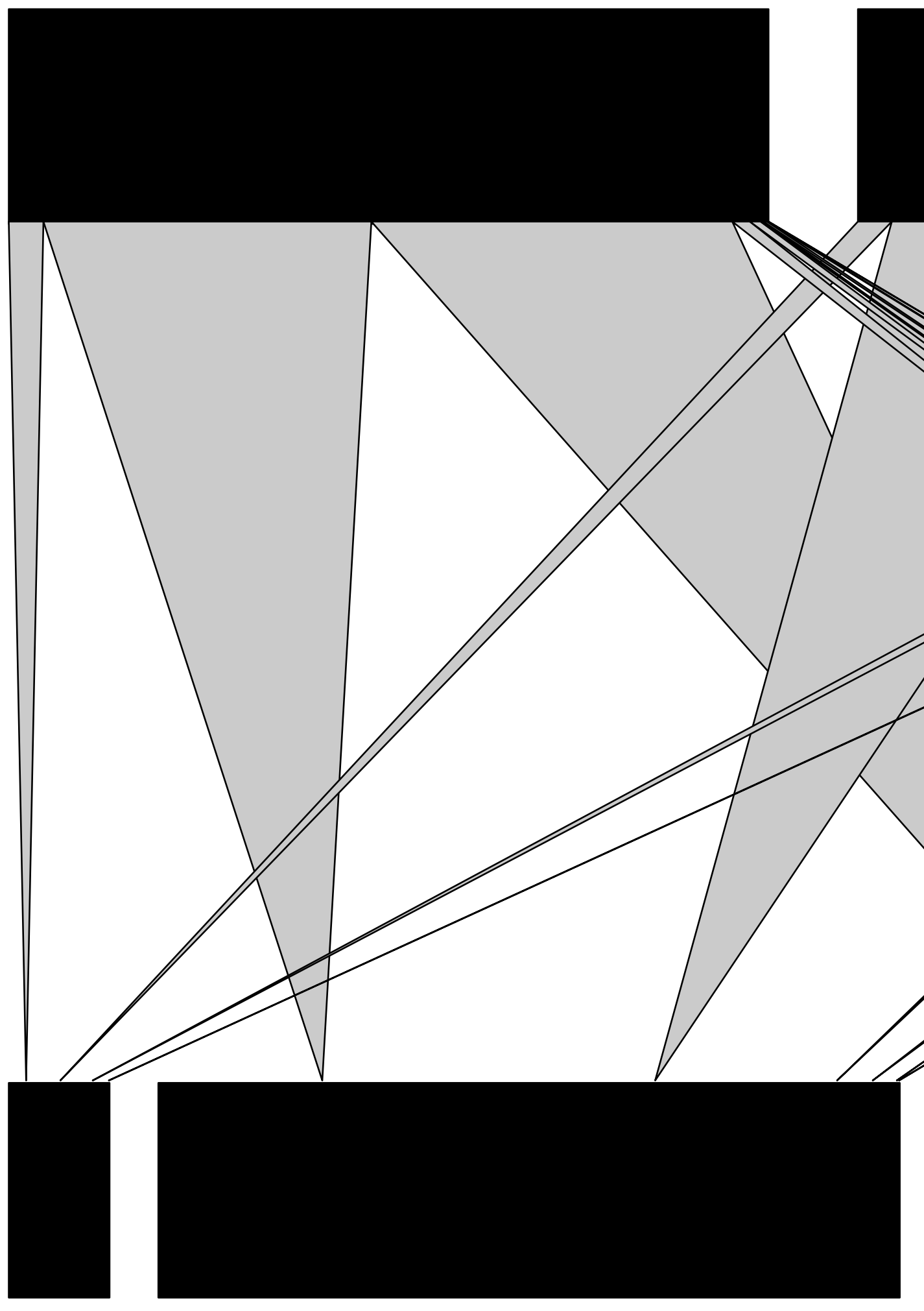

Pied flycatcher $(n=29)$
Blue tit

$(n=112)$
Monopis laevigella
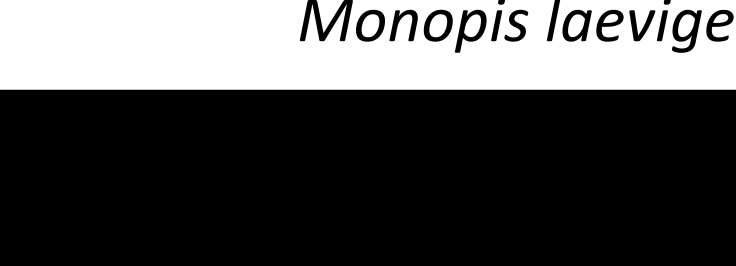

\section{$-$}
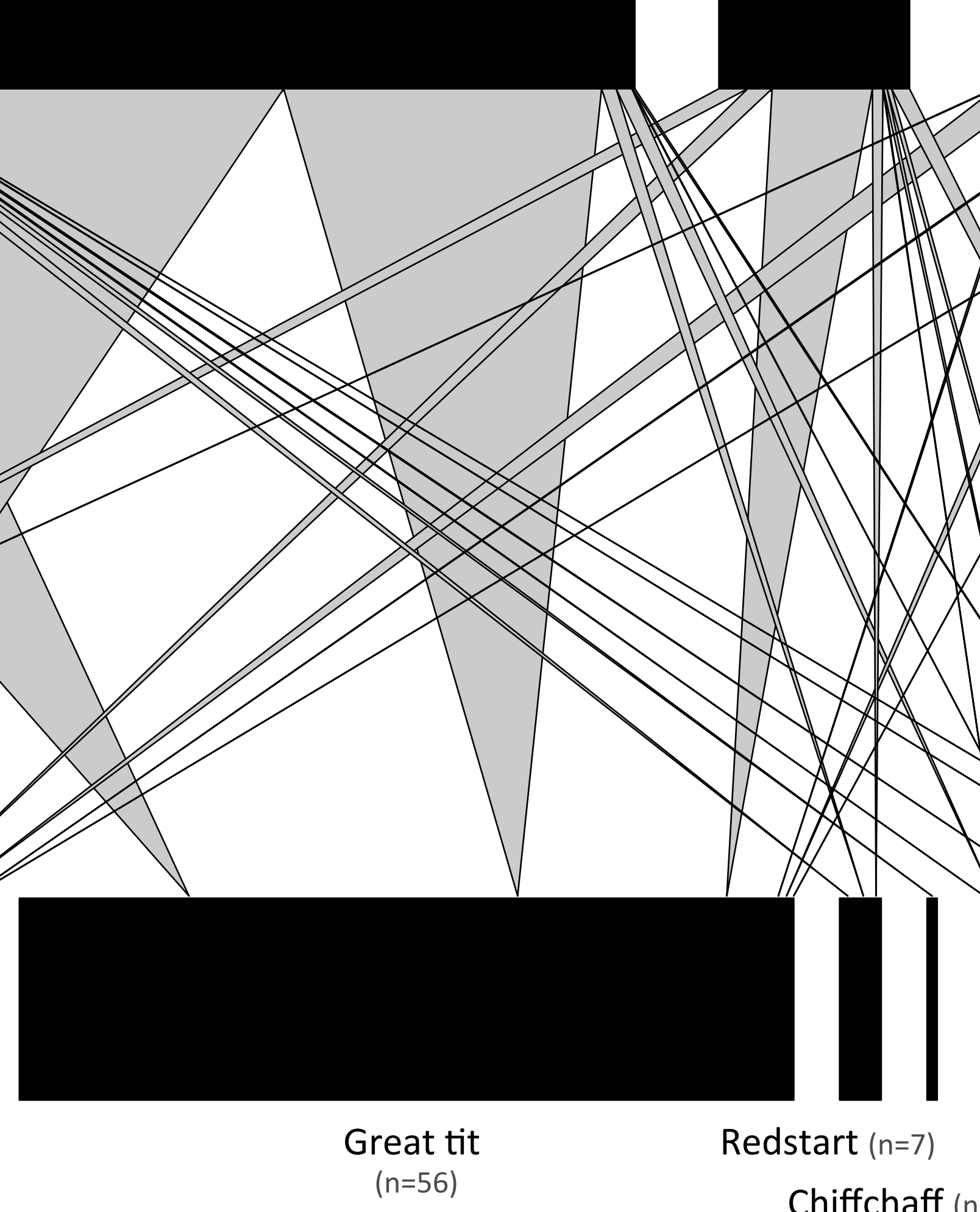

Redstart ( $n=7)$

Wren $(n=1)$

Stock Dove $(n=1)$

Chiffchaff $(n=1) \quad$ Nuthatch $(n=1)$

Coal tit $(n=1) \quad$ Garden Warbler $(n=1)$

Blackbird $(n=7)$ Wood Warbler $(n=1)$ 